\title{
2078 High prevalence of cardiac hypertophy without detectable signs of fibrosis in patients with untreated active acromegaly: an in-vivo study using magnetic resonance imaging and integrated backscatter analysis
}

\author{
Elisabetta Strata*1, Giovanni Donato Aquaro1, Fausto Bogazzi², \\ Chiara Sardella ${ }^{2}$, Vitantonio Di Bello ${ }^{3}$ and Massimo Lombardi ${ }^{1}$
}

\author{
Address: ${ }^{1}$ Institute of Clinical Physiology - CNR, Pisa, Italy, ${ }^{2}$ Department of Endocrinology and Metabolism, University of Pisa, Pisa, Italy and \\ ${ }^{3}$ Cardiothoracic Department, University of Pisa, Pisa, Italy \\ * Corresponding author
}

from I th Annual SCMR Scientific Sessions

Los Angeles, CA, USA. I-3 February 2008

Published: 22 October 2008

Journal of Cardiovascular Magnetic Resonance 2008, I (Suppl I):A347 doi:I0.I I86/I532-429X-10-SI-A347

This abstract is available from: http://jcmr-online.com/content/I0/SI/A347

(C) 2008 Strata et al; licensee BioMed Central Ltd.

\section{Introduction}

Left ventricular (LV) hypertrophy and myocardial fibrosis are considered the main pathological features of acromegalic cardiomyopathy. Cardiovascolar Magnetic Resonance (CMR) allows to detect myocardial gross fibrosis using the delayed enhancement (DE) technique. Myocardial echointensity as derived by integrated backscatter (IBS) echocardiographic analysis is considered an index of myocardial collagen content.

\section{Purpose}

The aim of the study was to evaluate the proportion of $\mathrm{LV}$ hypertrophy and the presence of gross fibrosis and microscopic collagen content in acromegalic cardiomyopathy in vivo.

\section{Methods}

Fourteen consecutive patients (eight women, mean age 46 \pm 10 years) with untreated active acromegaly were submitted to two-dimensional (2D) colour Doppler and integrated backscatter (IBS) echocardiography and CMR. CMR was performed using to 1.5-T MR scanner (CV/I, GE, Milwaukee, WI). LV volume, mass and wall thickness were obtained using FIESTA short axis images $(8 \mathrm{~mm}$ slice thickness, no gap, 30 phases) covering the entire LV.
Delayed enhancement images were acquired in short axis views 10 minutes after contrast media(gadobutrol 0.2 $\mathrm{mmol} / \mathrm{Kg}$ ) injection. A software developed ad hoc was used to quantify delayed enhancement techinque. A detailed IBS methodology has been described previously [1]. Control settings for the imaging chain, such as preprocessing, focus position, persistence, compression, frame installments and postprocessing, to were maintained constant for all the participants. End-diastolic IBS parameters to were then indexed for IBS pericardial values at the posterior wall (IBSpwi). The pericardial interface reflectivity was considered, for to static reflectivity pattern, to be equal to $100 \%$ of the IBS reflectivity of the cardiac structures. The reflectivity of the posterior wall was indexed for pericardial reflectivity to optimize the comparability of each patient, avoiding the reflectivity differences linked to artefacts two to attenuation phenomena. Normal IBSpwi was defined $<45 \%$.

\section{Results}

On echocardiography: mean LV mass (LVM) and LVM index (LVMi) were $209 \pm 48 \mathrm{~g}$ and $110 \pm 24 \mathrm{~g} / \mathrm{m} 2$, respectively; hypertrophy was revealed in five patients $(36 \%)$; abnormal diastolic function [evaluated by isovolumic relaxation time (IVRT) or early (E) to late or atrial (A) peak velocities (E/A ratio)] was found in four patients 
(29\%). Systolic function evaluated by measuring LV ejection fraction (LVEF) was normal (mean $72 \pm 12 \%$ ) in all patients. Six patients (43\%) had increased IBS (mean 57.4 $\pm 6.2 \%)$. On CMR: mean LVM and LVMi were $151 \pm 17 \mathrm{~g}$ and $76 \pm 9 \mathrm{~g} / \mathrm{m} 2$, respectively; 10 patients $(72 \%)$ had LV hypertrophy. Delayed hyperenhancement was absent in all patients; on the contrary a mild enhancement was revealed in one patient. IBSpwi was abnormal in 6 patients $(42.8 \%)$. Systolic function was normal in all patients (LVEF $67 \pm 11 \%$ ). LVMi was not related to serum IGF-1 concentrations or the estimated duration of disease.

\section{Conclusion}

CMR is considered to be the gold standard for evaluating cardiac hypertrophy, fibrosis and systolic function. Using CMR, $72 \%$ patients with untreated active acromegaly had LV hypertrophy, which was only detected in $36 \%$ patients by echocardiography. However, cardiac fibrosis was absent in all patients irrespective of the estimated duration of disease. Although a very small increase in collagen content (as suggested by increased cardiac reflectivity at IBS), not detectable by CMR, could not be ruled out, it is unlikely that it would significantly affect cardiac function.

\section{References}

I. Bogazzi F, Di Bello V, Palagi C, Delle Donne MG, Di Cori A, Gavioli S, Talini E, Cosci C, Sardella C, Brogioni S, Mariani M, Martino E: Improvement of intrinsic myocardial contractility and cardiac fibrosis degree in acromegalic patients treated with somatostatin analogues: a prospective study. Clinical Endocrinology 2005, 62:590-596.
Publish with Bio Med Central and every scientist can read your work free of charge

"BioMed Central will be the most significant development for disseminating the results of biomedical research in our lifetime. " Sir Paul Nurse, Cancer Research UK

Your research papers will be:

- available free of charge to the entire biomedical community

- peer reviewed and published immediately upon acceptance

- cited in PubMed and archived on PubMed Central

- yours - you keep the copyright

Submit your manuscript here:

http://www.biomedcentral.com/info/publishing_adv.asp 